\title{
The Role of Prandial Pramlintide in the Treatment of Adolescents With Type 1 Diabetes
}

\author{
LUISA M. RODRIGUEZ, KIMBERLY J. MASON, MOREY W. HAYMOND, AND RUBINA A. HEPTULLA \\ Department of Pediatrics, Division of Diabetes and Endocrinology, Texas Children's Hospital, Baylor College of Medicine, \\ Houston Texas 77030
}

\begin{abstract}
Pramlintide, a synthetic analog of amylin, improves postprandial hyperglycemia. We compared subcutaneous (s.c.) pramlintide injection with square wave pramlintide infusion in adolescents with type 1 diabetes (T1DM). Eight subjects with T1DM underwent two randomized studies. Subcutaneous pramlintide (dose $=5 \mu \mathrm{g} / \mathrm{unit}$ of insulin) bolus, was given one time and another time, the same dose was given as a 120-min s.c. infusion. Insulin dose was constant between studies. Gastric emptying was assessed with oral acetaminophen and $\left[1-{ }^{13} \mathrm{C}\right]$ glucose in meal. Plasma glucagon, pramlintide, and insulin concentrations were measured. Insulin concentrations $(p<$ 0.99 ) between pramlintide injection versus infusion were similar; however, glucose concentrations were different $(p<0.0001)$, with the absence of hypoglycemia during pramlintide infusion [AUC $(0-120 \mathrm{~min})-0.07 \pm 0.2$ versus $1.05 \pm 0.24 \mathrm{mg} * \mathrm{~h} / \mathrm{dL}(p<$ $0.0088)]$. Insulin-only administration resulted in postprandial hyperglycemia and late postprandial hypoglycemia $(p<0.0001)$. Two subjects experienced hypoglycemia with pramlintide injection. Pramlintide bolus caused pronounced glucagon suppression $(p<0.0003)$ and delayed gastric emptying as $\left(\left[{ }^{13} \mathrm{CO}_{2}\right] p<0.0003\right.$ and acetaminophen $p<0.01)$ compared with infusion. We conclude that pramlintide bolus may result in an increase in risk of immediate postprandial hypoglycemia. Further modifications in pramlintide delivery are indicated before it can be safely used in children. (Pediatr Res 62: 746-749, 2007)
\end{abstract}

$\beta$ Cells of the pancreas cosecrete insulin and amylin $(1,2)$. Type 1 diabetes (T1DM) is characterized by $\beta$-cell loss. Consequently, there are both insulin and amylin deficiencies (3). Amylin is thought to play a role in decreasing immediate postprandial glucose excursions (4) by delaying gastric emptying and glucagon suppression. Pramlintide acetate, a synthetic analog of amylin, effectively reproduces amylin agonist activity and is found to be effective in decreasing immediate postprandial hyperglycemia (5-8).

We previously reported that children with T1DM, compared with controls, demonstrate marked postprandial hyper-

Received July 6, 2007; accepted July 24, 2007.

Correspondence: Rubina A. Heptulla, M.D., Texas Children's Hospital, 6621 Fannin Street, Houston, TX 77030; e-mail: heptulla@bcm.tmc.edu

L.M.R. is supported by an NIDDK award T32 DK063873-02 and M.W.H. is supported by NIDDK grant R01 DK0555478 and CNRC (CRIS)-2533710353. Grants awarded to R.A.H.: NIH grant DK065059 and R01DK077166-01 and Juvenile Diabetes Research Foundation Regular Research Grant. This study received only drug from Amylin Pharmaceuticals Inc with no monitory support.

This work is a publication of the USDA/ARS Children's Nutrition Research Center, Department of Pediatrics, Baylor College of Medicine, Houston, TX. The contents of this publication do not necessarily reflect the views of policies of the U.S. Department of Agriculture, nor does mention of trade names, commercial products, or organizations imply endorsement from the U.S. government. glycemia despite the use of insulin pump therapy and a good hemoglobin A1C (hemoglobin $\mathrm{A}_{1 \mathrm{c}}\left[\mathrm{HbA}_{1 \mathrm{c}}\right]$ ) (9). Postprandial glucose excursions failed to normalize despite a $60 \%$ increase in the premeal insulin bolus. Adjunctive use of pramlintide acetate with insulin effectively decreased immediate postprandial hyperglycemia. However, five of the eight subjects studied had immediate postprandial hypoglycemia, which was treated using small amounts of intravenous (i.v.) glucose. If delayed gastric emptying is the predominant effect of pramlintide action, then pramlintide injection may result in decreased carbohydrate absorption during peak pramlintide concentration. Postprandial hyperglycemia was also noted in the late postprandial period, indicating that there may be sudden glucagon or gastric content release resulting in this paradoxical glucose excursion. Previously, Kong et al. (10) demonstrated profound suppression of both solid and liquid phase of gastric emptying with i.v. pramlintide infusion . Hence, we hypothesized that pramlintide bolus injection will result in acute suppression of glucagon and gastric emptying that increases the risk of postprandial hypoglycemia while in the late postprandial period the sudden release of gastric content and or glucagon escape results in late postprandial hyperglycemia. The current study was undertaken to examine the role of administering pramlintide acetate either as a s.c. infusion over a 2-h period versus giving the same dose as a bolus injection before a mixed meal in T1DM and its effect on postmeal glucose excursions. Furthermore, we have characterized the effect of pramlintide on gastric emptying and glucagon. To our knowledge, this is the first study comparing pramlintide infusion to s.c. injection. Furthermore, this is the second report of pramlintide administration in pediatric T1DM.

\section{METHODS}

The Institutional Review Board of Baylor College of Medicine approved this investigator-initiated study. Amylin Pharmaceuticals, Inc. played no role in the design, implementation, or interpretation of these data. Informed consent was obtained in accordance with federal and institutional guidelines before entry into this trial.

Subjects. From our population of 1200 patients with T1DM, we approached patients aged $12-18$ y who were on s.c. insulin pump therapy. Subjects had normal body mass index (BMI) $(<90$ th percentile for age) and $\mathrm{Hb} \geq 12 \mathrm{~g} / \mathrm{dL}$ and were in moderate glycemic control with $\mathrm{HbA}_{1 \mathrm{c}} \leq 8.5 \%$. They had no other chronic conditions besides diabetes with or without hypothyroidism and were on no medications that affect glucose concentrations

Abbreviations: $\mathbf{H b A}_{\mathbf{1 c}}$, hemoglobin $\mathrm{A}_{1 \mathrm{c}}$; T1DM, type 1 diabetes 
Table 1. Clinical characteristics

\begin{tabular}{lcc}
\hline \multicolumn{1}{c}{ Characteristic } & Control & Pramlintide \\
\hline Age $(\mathrm{y})$ & $16 \pm 0.3$ & $17.4 \pm 0.01$ \\
Sex (male/female) & $7 / 4$ & $6 / 2$ \\
Duration of diabetes $(\mathrm{y})$ & $4.7 \pm 0.7$ & $5.3 \pm 1.3$ \\
$\mathrm{BMI}\left(\mathrm{kg} / \mathrm{m}^{2}\right)$ & $23 \pm 0.8$ & $20.3 \pm 0.08$ \\
$\mathrm{HbA}_{\mathrm{lc}}(\%)$ & $7.7 \pm 0.1$ & $7.3 \pm 0.3$ \\
Systolic blood pressure $(\mathrm{mm} \mathrm{Hg})$ & $122 \pm 6$ & $133 \pm 3$ \\
Diastolic blood pressure $(\mathrm{mm} \mathrm{Hg})$ & $66 \pm 2$ & $71 \pm 2$ \\
Pulse (beats/min) & $79 \pm 4$ & $79 \pm 6$ \\
\hline
\end{tabular}

Data are expressed as mean $\pm \mathrm{SEM}$.

(except insulin). Subjects had a normal physical examination and were Tanner staged.

Pregnant and lactating females were excluded from the study. A total of nine subjects with T1DM were screened. Eight subjects with T1DM completed both studies. The clinical characteristics are shown in Table 1. One subject opted out after receiving pramlintide infusion. The subject experienced nausea and vomiting associated with pramlintide administration and i.v. access problems. Control subjects did not have any side effects.

Study design. Subjects with T1DM underwent two studies in random order. On one occasion, subjects received pramlintide as a bolus injection just before the meal; on the other occasion (4-6 wk apart), the same subjects received pramlintide as an s.c. infusion of the same dose of pramlintide. Data were also compared with our previous report wherein 11 T1DM subjects underwent a study identical in every respect to the current protocol with the exception that subjects did not receive pramlintide. Data on gastric emptying were not collected in the control experiment, and only data on eight subjects were previously reported (9). The time between the control studies and pramlintide study was 8 mo to $1 \mathrm{y}$.

On the day before the study, subjects were admitted to the General Clinical Research Center (GCRC) for overnight management of their blood glucose concentrations. Subjects were on an insulin pump with short-acting insulin analogs: lispro or aspart. Usual insulin doses were administered with a standard dinner (composed of 60-80 $\mathrm{g}$ of carbohydrate, and the macronutrient composition was $60 \%$ carbohydrates, $20 \%$ protein, and $20 \%$ fat) and bedtime snack ( $30 \mathrm{~g}$ of carbohydrate and a similar macronutrient composition as the dinner). The meal amounts were matched between all three studies. At $2200 \mathrm{~h}$, an indwelling i.v. line was started in one of the antecubital veins to draw blood and administer glucose in the event of hypoglycemia. Reflectance meter blood glucoses were done every $60 \mathrm{~min}$ from 2200 to 0300 and every $30 \mathrm{~min}$ from 0300 to 0800 . Blood glucose was maintained between 5 and 7.2 $\mathrm{mM}$ by varying the rate of s.c. continuous insulin infusion. Hypoglycemia was avoided by giving $2-7 \mathrm{~g}$ of i.v. glucose if the blood glucose was $<4.4 \mathrm{mM}$.

On the morning of the study, a second indwelling line was placed in the contralateral antecubital space or forearm/hand vein as back-up access in the event of hypoglycemia. Baseline blood samples of glucose, insulin, pramlintide, and glucagon were drawn before study start. The subjects then received an insulin bolus just before test meal, which was based on a standard meal and their usual insulin-to-carbohydrate ratio. Insulin was given as a bolus via an insulin pump. Pramlintide was calculated based on the insulin dose $(5 \mu \mathrm{g}$ of pramlintide/unit of insulin). Pramlintide was given either as an s.c. bolus using a separate syringe or as a square wave bolus over a 120 -min period by an s.c. infusion pump. The dose of pramlintide was identical in both studies. At time 0, subjects drank a standard liquid meal of Boost High Protein Drink $12 \mathrm{oz}$ (360 calories, $50 \mathrm{~g}$ of carbohydrate, $9 \mathrm{~g}$ of fat, and $22 \mathrm{~g}$ of protein) over a period of $10 \mathrm{~min}$. The liquid meal was enriched with $1 \mathrm{~g}$ of $\left[1-{ }^{13} \mathrm{C}\right] \mathrm{glucose}$, and breath samples for ${ }^{13} \mathrm{CO}_{2}$ analysis were collected in two tubes at 17 time points during the study. In addition to $\left[{ }^{13} \mathrm{C}\right]$ glucose measurements, acetaminophen was given $20 \mathrm{mg} / \mathrm{kg}$ orally as a marker for gastric emptying. Blood samples for insulin and glucagon were drawn at 10- to 30-min intervals for $300 \mathrm{~min}$. Blood glucose was measured at the bedside using a glucose analyzer (YSI 2300 Stat Plus, Yellow Springs Instruments Company Inc., Yellow Springs, $\mathrm{OH}$ ) at 10 -min intervals from $-60 \mathrm{~min}$ to $300 \mathrm{~min}$. Blood samples were obtained before pramlintide dosing and at 20,40,60,120,180,240, and 300 min following drug administration. Acetaminophen sampling was done at the following time points: $-10,30,60,100,180$, and $300 \mathrm{~min}$. Following collection, samples were immediately centrifuged at $5000 \times g$ for 5 min and stored at $\leq-20^{\circ} \mathrm{C}$ until analysis. During the study, if the subject's blood glucose values were $<3 \mathrm{mM}$, i.v. glucose $(5-7 \mathrm{~g})$ was given to correct low blood glucose.

Control study. Eleven control subjects with T1DM (previously reported study) who received only insulin and no pramlintide were compared with subjects who received pramlintide either as an infusion or injection in addition to insulin. The study protocols were identical except that in the control study, data on gastric emptying were not obtained.

Measurements. Blood glucose concentrations were measured using a glucose analyzer (YSI 2300 Stat Plus, Yellow Springs Instruments Company Inc.). The DCA $2000 \mathrm{Hb}$ A1C System (Bayer, Elkhart, IN) was used for measuring the percentage concentration of $\mathrm{HbA}_{1 \mathrm{c}}$ in the blood. The assay is based on a latex immunoagglutination inhibition method. Both the concentration of $\mathrm{HbA}_{1 \mathrm{c}}$ specifically and the concentration of total $\mathrm{Hb}$ are measured, and the ratio reported as percent $\mathrm{HbA}_{1 \mathrm{c}} . \mathrm{HbA}_{1 \mathrm{c}}$ concentration in the range of $2.5 \%$ to $>14.0 \%$ is reported.

An ultrasensitive radioimmunoassay determines ultrafiltrate insulin with a detection limit of $0.5 \mu \mathrm{U} / \mathrm{mL}$. Glucagon was measured using an immunoassay specific to pancreatic glucagon with $4.5 \%$ intra-assay variability and a $7.1 \%$ interassay variability. All kits used were purchased from Linco Research Inc. Plasma pramlintide concentrations were measured by Amylin Pharmaceuticals, Inc., using a validated two site-specific immunoradiometric assay (11). ${ }^{13} \mathrm{CO}_{2}$ was measured in breath samples using an isotopic mass spectrometer (Thermo-Finnigan Gas Bench-II coupled with Finnigan Delta + XL IRMS). The expired ${ }^{13} \mathrm{CO}_{2}$ after test drink ingestion of the oral liquid meal was compared with the baseline value, and results were expressed as an absolute increase in ${ }^{13} \mathrm{C}$ in $\delta \%$ (12). MDS Pharma Services using a high-performance liquid chromatography methodology assayed acetaminophen.

Statistics. Repeated-measures analysis of variance (ANOVA) was used to analyze glucose and hormonal excursions. Paired comparisons were made for pramlintide studies and unpaired comparisons were made for control study to pramlintide administration. Significance was considered at a 0.05 level, post $h o c$ analysis using a paired two-tailed $t$ test was applied. GraphPad Prism 4.0 was used for data analysis. Area under the curve (AUC) was analyzed using the trapezoidal rule using Excel version 7.0.

\section{RESULTS}

Glucose and insulin concentrations. Figure 1 depicts the plasma concentrations of glucose and insulin before and after a meal in T1DM subjects with and without pramlintide use. In the control study, when subjects received only insulin, glucose excursions were increased and remained higher for an extended period of time compared with adjunctive pramlintide infusion. However, pramlintide injection resulted in immedi-
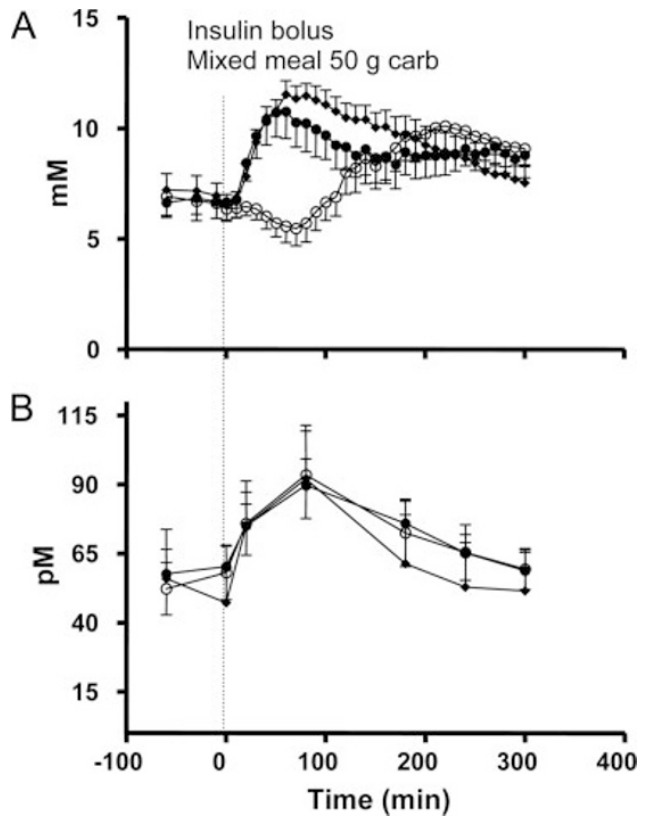

Figure 1. Plasma glucose $(p<0.0001)(A)$ and insulin $(p>0.99)(B)$ concentrations in children with T1DM after a mixed meal. Control study: no adjunctive pramlintide $(\checkmark)$ administered, pramlintide administered as an infusion $(\bigcirc) v s$ given as an s.c. bolus injection $(\bigcirc)$ before a mixed meal ingestion of $50 \mathrm{~g}$ of carbohydrates and insulin bolus. Data are mean \pm SEM. 
ate postprandial glucose fall and then a rise in glucose over the next $3 \mathrm{~h}(p<0.0001)$. Pramlintide infusion resulted in a postprandial glucose rise followed by glucose concentrations that did not reach preprandial concentrations. When the AUC was compared, pramlintide injection resulted in lowering of immediate postprandial glucose compared with an infusion [AUC $(0-120 \mathrm{~min})-0.07 \pm 0.2$ versus $1.05 \pm 0.24 \mathrm{mg} * \mathrm{~h} /$ dL) $(p<0.0088)]$.

Glucagon suppression and gastric emptying. Figure 2 demonstrates that glucagon concentrations were suppressed in response to a bolus injection compared with an infusion $(p<$ 0.0003). Gastric emptying as measured by ${ }^{13} \mathrm{CO}_{2}$ in breath and

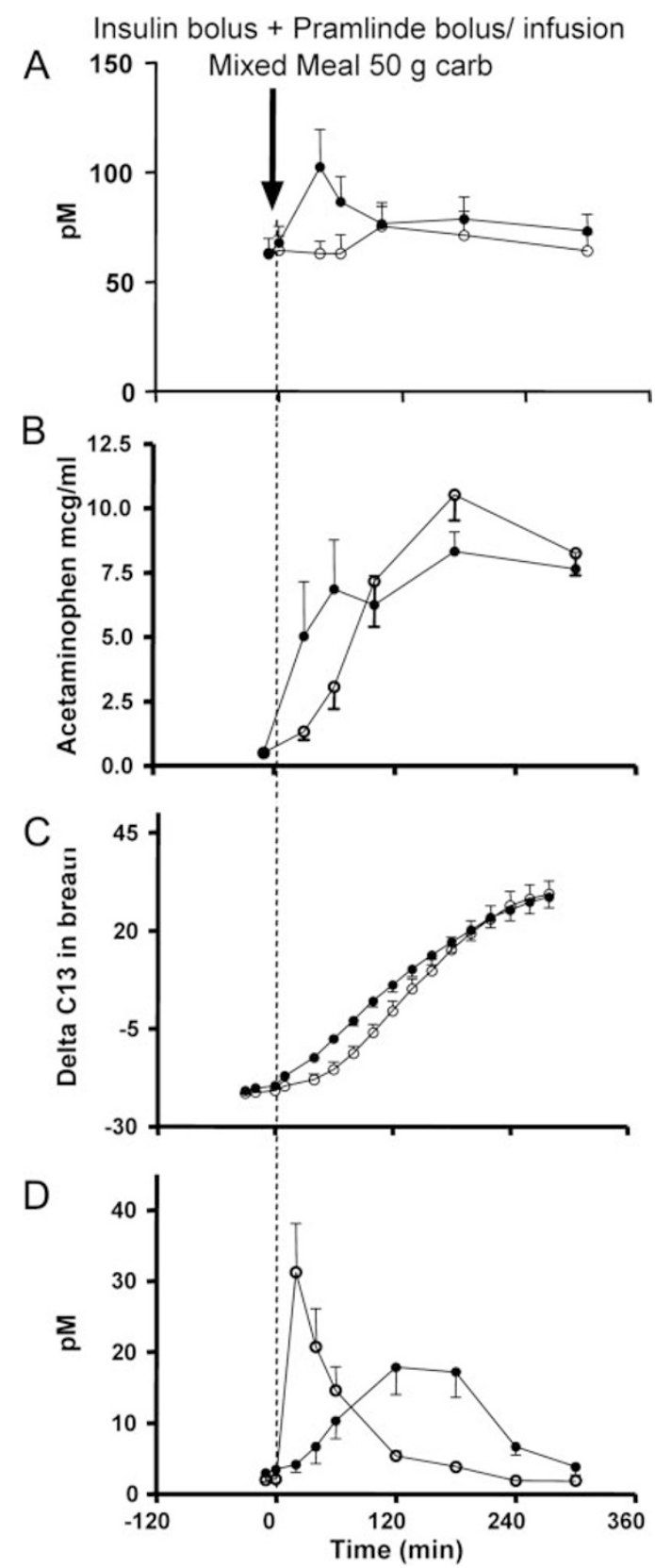

Figure 2. Glucagon $(p<0.003)(A)$, acetaminophen $(p<0.01)(B),{ }^{13} \mathrm{CO}_{2}$ breath analysis $(p<0.0001)(C)$, and pramlintide concentrations $(p<0.02)$ $(D)$ measured when pramlintide administered as an infusion $(\bullet) v s$ given as an s.c. bolus injection $(\bigcirc)$ before a mixed meal ingestion of $50 \mathrm{~g}$ of carbohydrates and insulin bolus. Data are mean \pm SEM. acetaminophen concentrations were significantly suppressed when pramlintide was given as a bolus injection compared with infusion. The changes in gastric emptying and glucagon suppression occurred during peak pramlintide action after the injection.

Adverse events. All subjects had lowering of blood glucose after pramlintide injection in the range of 3.3-3.8 mM. Two subjects who received pramlintide injection experienced hypoglycemia after the meal and required additional i.v. glucose per protocol. One subject had a nadir of $2.2 \mathrm{mM}$ at $90 \mathrm{~min}$ and one subject had a nadir of 2.64 at $80 \mathrm{~min}$. One subject who received pramlintide infusion had nausea and vomiting.

\section{DISCUSSION}

This study investigates the role of pramlintide acetate given as an s.c. infusion rather than a bolus injection. These data demonstrate that pramlintide acetate causes an acute reduction in glucose concentrations when given as a bolus injection. Greater delay in gastric emptying and glucagon suppression was noted when pramlintide acetate injection was administered as a bolus rather than an infusion, and these effects coincided with lower blood glucose concentrations.

Previously, we showed that five of eight subjects had immediate postprandial hypoglycemia and four received i.v. glucose to treat low blood glucose. In this study, lowering of prandial pramlintide bolus dose and using pramlintide as a function of insulin resulted in decreased glycemic excursions. However, despite these changes, two patients required i.v. glucose as per protocol when pramlintide bolus injection resulted in immediate postprandial hypoglycemia. The insulin-to-pramlintide ratio used in our study will decrease the incidence of postprandial hypoglycemia, and in the clinical setting, this ratio can be individualized and daily activities and exercise be taken in to consideration. Decreasing insulin doses can also diminish this risk of hypoglycemia (13). In our study, we did not change insulin dose but changed the mode of delivery of pramlintide to a square wave s.c. infusion to determine whether the intervention would alter glucose excursions. A combination of changes may be required in the clinical setting to eliminate the risk of immediate postprandial hypoglycemia (14).

Both gastric emptying and glucagon suppression occur as a result of pramlintide administration. However, this suppression is more profound with the injection compared with the infusion. One of the limitations of our study is that we were unable to compare glucagon and gastric modulation in control patients who did not receive pramlintide. Modulation of gastric emptying as a means of decreasing postprandial hyperglycemia has been previously examined. The alphaglucosidase inhibitors, such as acarbose and miglitol, delay gastric emptying and decrease postprandial hyperglycemia (15) by modulating delivery of carbohydrates to the gut. However, their use is limited due to their side effects (16). Intravenous pramlintide profoundly slows gastric emptying (10); hence, in our study, we use pramlintide subcutaneously. We used two measures for gastric emptying because we wanted to substantiate it by two different methods. In addition, 
$\left[1-{ }^{13} \mathrm{C}\right]$ glucose will allow us in the future to examine gastric emptying in children in a noninvasive way with no additional blood samples. Currently, we are examining the role of using two pumps: one for insulin and the other for adjunctive pramlintide to determine the dose that may be required during pre- and the postprandial periods to prevent postprandial hyperglycemia and late preprandial hypoglycemia.

Timing of pramlintide delivery has been previously examined by Weyer et al. (17), and they found that giving pramlintide before meal was the only way to decrease immediate postprandial hyperglycemia. Hence, our study used pramlintide before meal, but it may be that a much higher dose of pramlintide is required right at the start of the meal to prevent immediate postprandial hyperglycemia, which did not occur with using a square wave bolus. A different type of bolus such as a dual wave bolus may yield more favorable glucose results, and studies to examine that question are currently being done in our laboratory.

The role of preventing hypoglycemia with the use of glucagon has been investigated by many studies $(9,18-20)$. However, the use of pramlintide may obviate the need to use exogenous glucagon, and endogenous glucagon modulation may decrease both late postprandial hypoglycemia and suppression of glucagon may decrease immediate postprandial hyperglycemia (21). Pramlintide in addition to hypoglycemia can result in nausea. However, compared with our earlier report (9), only one subject suffered from nausea. The lowered pramlintide dose may have resulted in the decreased incidence of nausea in this study. This is an improvement from our earlier report wherein there were two subjects who had nausea and one subject who had vomiting. In long-term studies, nausea can occur in the first weeks of initiation of treatment $(13,22)$. Although the exact mechanism of this side effect is not known, amylin binds to the area postrema, which is colocated with the chemoreceptor trigger zone resulting in nausea and/or vomiting. Commencing pramlintide at a low dose, especially in the first week, may lower the risk of nausea, and further studies in refining the insulin-topramlintide ratio would allow physicians flexible dosing.

In summary, our results suggest that modulating gastric emptying and/or glucagon suppression occurs with the use of adjunctive pramlintide in the treatment of T1DM patients. Pramlintide injection can decrease immediate postprandial hyperglycemia and should be used with caution with appropriate information to patients regarding risk of hypoglycemia. More studies are needed to determine whether continuous s.c. pramlintide infusion has a role in preventing postprandial hyperglycemia and preventing meal pramlintide injection related hypoglycemia. Ongoing studies in our laboratory using variations of boluses such as dual wave and regular wave are currently under way. These studies will allow us in the future to use pramlintide in a safe and effective way in patients with T1DM.
Acknowledgments. The authors thank the GCRC nurses for the nursing assistance provided for this study. Drs. Orville Kolterman, David Maggs, and Mark Fineman were very helpful in providing the drug and pramlintide assay analysis (no monetary support was provided).

\section{REFERENCES}

1. Gedulin BR, Rink TJ, Young AA 1997 Dose-response for glucagonostatic effect of amylin in rats. Metabolism 46:67-70

2. Moore CX, Cooper GJ 1991 Co-secretion of amylin and insulin from cultured islet beta-cells: modulation by nutrient secretagogues, islet hormones and hypoglycemic agents. Biochem Biophys Res Commun 179:1-9

3. Koda JE, Fineman M, Rink TJ, Dailey GE, Muchmore DB, Linarelli LG 1992 Amylin concentrations and glucose control. Lancet 339:1179-1180

4. Thompson RG, Peterson J, Gottlieb A, Mullane J 1997 Effects of pramlintide, an analog of human amylin, on plasma glucose profiles in patients with IDDM: results of a multicenter trial. Diabetes 46:632-636

5. Samsom M, Szarka LA, Camilleri M, Vella A, Zinsmeister AR, Rizza RA 2000 Pramlintide, an amylin analog, selectively delays gastric emptying: potential role of vagal inhibition. Am J Physiol Gastrointest Liver Physiol 278:G946-G951

6. Kong MF, King P, Macdonald IA, Blackshaw PE, Perkins AC, Armstrong E, Buchanan KD, Tattersall RB 1998 Effect of euglycaemic hyperinsulinaemia on gastric emptying and gastrointestinal hormone responses in normal subjects. Diabetologia 41:474-481

7. Nyholm B, Orskov L, Hove KY, Gravholt CH, Moller N, Alberti KG, Moyses C, Kolterman O, Schmitz O 1999 The amylin analog pramlintide improves glycemic control and reduces postprandial glucagon concentrations in patients with type 1 diabetes mellitus. Metabolism 48:935-941

8. Fineman M, Weyer C, Maggs DG, Strobel S, Kolterman OG 2002 The human amylin analog, pramlintide, reduces postprandial hyperglucagonemia in patients with type 2 diabetes mellitus. Horm Metab Res 34:504-508

9. Heptulla RA, Rodriguez LM, Bomgaars L, Haymond MW 2005 The role of amylin and glucagon in the dampening of glycemic excursions in children with type 1 diabetes. Diabetes 54:1100-1107

10. Kong MF, Stubbs TA, King P, Macdonald IA, Lambourne JE, Blackshaw PE, Perkins AC, Tattersall RB 1998 The effect of single doses of pramlintide on gastric emptying of two meals in men with IDDM. Diabetologia 41:577-583

11. Percy AJ, Trainor DA, Rittenhouse J, Phelps J, Koda JE 1996 Development of sensitive immunoassays to detect amylin and amylin-like peptides in unextracted plasma. Clin Chem 42:576-585

12. Lewanczuk RZ, Paty BW, Toth EL 2004 Comparison of the [13C]glucose breath test to the hyperinsulinemic-euglycemic clamp when determining insulin resistance. Diabetes Care 27:441-447

13. Whitehouse F, Kruger DF, Fineman M, Shen L, Ruggles JA, Maggs DG, Weyer C, Kolterman OG 2002 A randomized study and open-label extension evaluating the long-term efficacy of pramlintide as an adjunct to insulin therapy in type 1 diabetes. Diabetes Care 25:724-730

14. Maggs DG, Fineman M, Kornstein J, Burrell T, Schwartz S, Wang Y, Ruggles JA, Kolterman OG, Weyer C 2004 Pramlintide reduces postprandial glucose excursions when added to insulin lispro in subjects with type 2 diabetes: a dose-timing study. Diabetes Metab Res Rev 20:55-60

15. Rabasa-Lhoret R, Burelle Y, Ducros F, Bourque J, Lavoie C, Massicotte D, Peronnet F, Chiasson JL 2001 Use of an alpha-glucosidase inhibitor to maintain glucose homoeostasis during postprandial exercise in intensively treated Type 1 diabetic subjects. Diabet Med 18:739-744

16. Fujisawa T, Ikegami H, Inoue K, Kawabata Y, Ogihara T 2005 Effect of two alpha-glucosidase inhibitors, voglibose and acarbose, on postprandial hyperglycemia correlates with subjective abdominal symptoms. Metabolism 54:387-390

17. Weyer C, Gottlieb A, Kim DD, Lutz K, Schwartz S, Gutierrez M, Wang Y, Ruggles JA, Kolterman OG, Maggs DG 2003 Pramlintide reduces postprandial glucose excursions when added to regular insulin or insulin lispro in subjects with type 1 diabetes: a dose-timing study. Diabetes Care 26:3074-3079

18. Monsod TP, Tamborlane WV, Coraluzzi L, Bronson M, Yong-Zhan T, Ahern JA 2001 Epipen as an alternative to glucagon in the treatment of hypoglycemia in children with diabetes. Diabetes Care 24:701-704

19. Haymond MW, Schreiner B 2001 Mini-dose glucagon rescue for hypoglycemia in children with type 1 diabetes. Diabetes Care 24:643-645

20. Stenninger E, Aman J 1993 Intranasal glucagon treatment relieves hypoglycaemia in children with type 1 (insulin-dependent) diabetes mellitus. Diabetologia 36:931-935

21. Fineman MS, Koda JE, Shen LZ, Strobel SA, Maggs DG, Weyer C, Kolterman OG 2002 The human amylin analog, pramlintide, corrects postprandial hyperglucagonemia in patients with type 1 diabetes. Metabolism 51:636-641

22. Kolterman OG, Schwartz S, Corder C, Levy B, Klaff L, Peterson J, Gottlieb A 1996 Effect of 14 days' subcutaneous administration of the human amylin analogue, pramlintide (AC137), on an intravenous insulin challenge and response to a standard liquid meal in patients with IDDM. Diabetologia 39:492-499 